\title{
2006-2053: ENGINEERING AND PUBLIC POLICY AT THE NANOSCALE: AN INTERDISCIPLINARY GRADUATE COURSE
}

\section{Jacqueline Isaacs, Northeastern University}

JACQUELINE A. ISAACS is an Associate Professor in the Department of Mechanical and Industrial Engineering at Northeastern University in Boston, MA. She is responsible for the education and outreach activities as well as research on societal implications for the NSF-sponsored Center for High-rate Nanomanufacturing $(\mathrm{CHN})$, a collaborative Center among NU, UML and UNH. Her research focuses on economic and environmental assessment of manufacturing.

\section{Christopher Bosso, Northeastern University}

Christopher J. Bosso is Associate Professor of political science at Northeastern University and a research faculty in the Nanotechnology and Society Research Group in the CHN. In addition to current work on regulatory dimensions of nanotechnology, Bosso writes on environmental and food safety policy, environmental politics, and public policymaking dynamics. His most recent scholarly work is Environment, Inc.: From Grassroots to Beltway (University Press of Kansas, 2005).

\section{Carol Barry, University of Massachusetts-Lowell}

CAROL M. F. BARRY is a Professor in the Department of Plastics Engineering at the University of Massachusetts in Lowell, MA. For CHN and at UML, she is the lead for the education and outreach activities for the NSF-sponsored CHN. Her research focuses on plastics processing, particularly at the micro and nanoscales and their application to high-rate nanomanufacturing. 


\title{
Engineering and Public Policy at the Nanoscale: An Interdisciplinary Graduate Course
}

\begin{abstract}
The excitement and promise of nanotechnology provides a unique opportunity to increase public awareness of the critical importance of science and technology to society in general and to students in particular. Nanotechnology and nanomanufacturing will require a more diverse technical education of the current and projected workforce. To increase student awareness of the societal implications of this developing technology, the academic partners in the Center for High-rate Nanomanufacturing (CHN), an NSF-sponsored Nanoscale Science and Engineering Center (NSEC), have created a team taught course entitled "Nanomanufacturing I". Assessment of engineering and science student performance is reported for the segment of the course that addressed policy issues.
\end{abstract}

\section{Introduction}

The academic partners in the Center for High-rate Nanomanufacturing (CHN), an NSFsponsored Nanoscale Science and Engineering Center (NSEC), have created a team taught course entitled "Nanomanufacturing I". Faculty from all three core partner academic institutions, including Northeastern University (NEU), University of Massachusetts at Lowell (UML), and the University of New Hampshire (UNH), have made contributions to the lectures, which were transmitted live each week to partner institutions with a two-hour duration to a student population with diverse scientific and engineering backgrounds on each campus during the Fall 2005 semester. The course was highly interdisciplinary in its technical content, and further, included topics delivered by faculty in social science and humanities. Twenty-three students were enrolled from NU, three students from UML and five students from UNH.

In 2002 the National Research Council made ten recommendations to strengthen the still-young National Nanotechnology Initiative, eventually incorporated into the NNI Strategic Plan (2004). Recommendation \#9 was that the National Science and Technology Council, Committee on Technology Subcommittee on Nanoscale Science, Engineering and Technology (NSET) "should develop a new funding strategy to ensure that the societal implications of nanoscale science and technology become an integral part of the NNI." Much has been done to meet this goal. Indeed, supported by the $21^{\text {st }}$ Century Nanotechnology Research and Development Act (PL 108-153: 2003), the NSF primarily, but other agencies as well (e.g., EPA, the National Institute for Occupational Health and Safety), have committed substantial funding toward understanding the social and environmental implications of the nanoscale revolution.

The intention for the course was not only to provide an interdisciplinary nanomanufacturing course for a student population with diverse scientific and engineering backgrounds, but also to increase the awareness in students, that the societal implications will have a direct impact on the development and implementation of the research upon which they are working. 


\section{Course Content, Logistics and Course Assessment}

\section{Course Content}

The "Nanomanufacturing I" course was offered among the three campuses that collaborate to form the Center for High-rate Nanomanufacturing. The course was organized into four segments, with professors at each of the three campuses were responsible for three week segments of material, and a fourth segment focusing on societal implications. In the first segment offered by NEU, the focus was on issues related to manufacturing of nanoelectronics.

Table 1: Weekly Course Topics

\begin{tabular}{|c|c|}
\hline WEEK & LECTURER and TOPICS \\
\hline \multirow{2}{*}{ Week 1} & $\begin{array}{l}\text { Busnaina: Nanomanufacturing and the Future: } \\
\text { Challenges for Nanoelectronics }\end{array}$ \\
\hline & $\begin{array}{l}\text { Papageorgiou: Basics of Semiconductor / MEMS } \\
\text { Fabrication }\end{array}$ \\
\hline \multirow[t]{2}{*}{ Week 2} & $\begin{array}{l}\text { Jung: Introduction to Carbon Nanotubes Properties } \\
\text { and Manufacturing }\end{array}$ \\
\hline & Somu: Optical and E-Beam Lithography \\
\hline \multirow{2}{*}{ Week 3} & $\begin{array}{l}\text { Busnaina: Surface Cleaning - the Removal of } \\
\text { Micro and Nanoscale lonic Particulate Defects }\end{array}$ \\
\hline & Dokmeci: Introduction to Nanotechnology \\
\hline Week 4 & Kay: Regulation 101 or Regulation for Engineers \\
\hline Week 5 & Barry: Manufacturing Polymer Nanocomposites \\
\hline Week 6 & Mead: Nanofibers by Electrospinning \\
\hline \multirow{2}{*}{ Week 7} & Mead: Nanolayered Polymers \\
\hline & Barry: Molding Small Things \\
\hline Week 8 & Ellenbecker: Assessing Exposures to Nanoparticles \\
\hline Week 9 & $\begin{array}{l}\text { Miller: Self-Assembly and Its Importance in } \\
\text { Nanomanufacturing }\end{array}$ \\
\hline Week 10 & Claverie: The Self-Assembly of Polymers \\
\hline Week 11 & $\begin{array}{l}\text { Pohl: Seeing is Believing: The Driving Forces of } \\
\text { Self-Assembly and Growth on Surfaces }\end{array}$ \\
\hline Week 12 & $\begin{array}{l}\text { Sandler: The Social and Ethical Dimensions of } \\
\text { Nanotechnology }\end{array}$ \\
\hline Week 13 & $\begin{array}{l}\text { Bosso: The Two Worlds - Scientists, Policymakers } \\
\text { and Implications for Nanotechnology }\end{array}$ \\
\hline
\end{tabular}

The second segment offered by faculty at UML focused on polymer processing at the nanoscale, and included a lecture on nanoparticle health and safety issues. The third segment offered by faculty at UNH focused on self-assembly of polymer molecules.

A fourth segment was interspersed among the three segments to include three one-week modules that addressed the regulatory and ethical issues involved with the development of nanomanufacturing technologies. In these sessions, students were asked to reflect on the potential societal implications of nanoscale research and manufacturing, including effects on worker safety, environment, and human health. In particular, students reflected on whether the touted benefits of nanotech come with very real side-effects that need to be kept in mind.

Because the course involved delivery of current and topical information, there was no single textbook that covered all topics, so students were referred to journal papers and web links on the course website. Each segment included fundamental concepts in addition to more advanced topics in nanomanufacturing. Course work included weekly homework and take-home. The weekly course topics are detailed in Table 1.

\section{$\underline{\text { Logistics }}$}

The course was offered as a separate course number at each university and in fact was offered for different semester hours, which influenced the required course work for 
students at different universities. (This difference resulted from differing time periods required for course approvals.) At NEU, the course was offered for 4 units, while at UML it was offered for 3 units, and at UNH, it was offered as a seminar course for 1 unit. Students at NEU and UML had required assignments, while students at UNH had no outside work. Further, additional weekly recitation / discussion sections were held so that students had additional time to talk with the lecturer about questions. Although all three universities are within an hour of each other, there were few occasions where the faculty from other universities held this recitation via conference calls.

The course was also offered out of different departments at each university, resulting in diverse student backgrounds. At NEU, students were primarily mechanical, chemical or electrical engineering degree programs, while at UML, students were from the plastics engineering degree program. At UNH, students were enrolled in the chemistry program. This diversity in student backgrounds sometimes made it difficult to address topical issues in the depth that faculty preferred.

The course was taught in "real-time" such that each week, the students met in the same room on their own campuses. During the first three weeks of the class, the lecture was broadcast from NEU to the other two campuses, with three-way audio communications. For the next five weeks, UML broadcast in real time, followed by three weeks of broadcast from UNH. The final two weeks were broadcast from NEU. In addition to the faculty lecturer at the broadcast location, faculty were present in each of the other two locations during class time to handle student questions.

\section{Course Assessment}

A web survey was conducted at the end of the course to gather student feedback on various aspects of the course, including 1) the logistical aspects of distance learning for each session, 2) the level of difficulty of the content presented by each lecturer, 3) level of difficulty of readings and homework and exams. Standard course evaluation forms were also used for collecting student comments. Based on initial student feedback from the first policy lecture, the policy and ethics lectures later in the term were adapted to accommodate student learning. In general, assessment indicated that students are interested in learning about the related policy and ethical issues, and that although there were significant challenges, the engineering and science students improved their understanding of these issues through this course.

\section{Assessment of Integrated Policy Lectures}

Three out of the thirteen weeks of lecture were devoted to topics broadly within the scope of science, technology, and society (STS) issues, with a particular focus on policy ramifications. These lectures were offered by faculty drawn from the Nanotechnology and Society Research Group (NSRG) at Northeastern University, formed in 2004 as part of the Nanoscale Science and Engineering Center for High-rate Nanomanufacturing to "assess the environmental, economic, regulatory, and ethical impacts of nanomanufacturing." Taken together, these three lectures sought to focus student attention to the societal and regulatory issues that will arise as nanotechnology moves from the laboratory to commercial production. 
Technology and regulation (Week 4). Professor William D. Kay, Department of Political Science, offered an overview of why governments historically have intervened in the market system to regulate emerging technologies or their side effects. Based on experiences with other new technologies, Kay noted that effective regulatory frameworks and institutions can serve to promote the advancement of research and development, promote more timely commercialization of products, protect the public from possible negative effects of these technologies and their use, and, in the process, be responsive to public concerns regarding technology. Morever, Kay observed, whatever their broader views about the "proper" role of government, citizens generally expect it to protect them from the potentially harmful effects of technology and its applications.

Social and ethical dimensions (Week 12). Professor Ronald Sandler, Department of Philosophy and Religion, discussed the kinds of societal concerns nanotechnology might encounter in the coming years. Using data from various surveys, Sandler assessed public knowledge about and attitudes toward nanotechnology, and tied these observations into efforts by the National Nanotechnology Initiative to elevate the capacity of citizens to understand nanotechnology issues and become active participants in both local and national discussions on them. These efforts are seen as crucial to maximizing the benefits of nanotechnology for U.S. citizens. Additionally, enhancing citizens' capacity to understand and more fully participate in policy decisions relating to nanoscale innovations contributes to the larger goal of enhancing democratic capacity writ large. The alternative may be public suspicion of and opposition to new applications. Experience with genetically modified organisms (GMOs) in agriculture is instructive. From the perspective of the concerned public, GMOs were a novel technology with potential environmental and human risks, and about which only limited information was available. Moreover, government agencies were not actively investigating these risks nor responding to concerns expressed by the public regarding consumers being exposed to GMOs involuntarily. Under those conditions, opposition was reasonable, even justified ${ }^{2}$.

Dimensions of public policymaking concerning risk (Week 13) Professor Christopher Bosso, Department of Political Science, concluded the course with a review of the classic C. P. Snow thesis on the "two worlds" of science and politics, and how these differences will affect policymaking on nanotechnology. For example, Bosso noted norms of scientific research-complete information, explanatory elegance, free dissemination of results--can clash with public policymakers' need to make decisions within short time horizons, often with incomplete information, and sometimes in contexts where information is guarded jealously for political or intellectual property reasons. In such instances, scientists may find their views subordinated to short-term political expediency or clashing with weight of other values, such as communal values, aesthetic values, and the good of animals and ecosystems. How are all of these values to be afforded due consideration? Does nanotechnology pose novel or particularly strong challenges to them? Bosso concluded by arguing that it will be crucial that researchers and product developers consider the extent to which, and how these "other values" will inform regulatory institutions and policy designs as nanoscale innovations begin to enter common use.

\section{Student Writing Assignment}

The essay assignment was intended to gauge how well students could apply the themes covered in the three lectures to the core science and technology material offered in other weeks. To do this, the students were asked to read an essay by science, technology and society scholar Michael 
Bennett ${ }^{1}$ that addressed issues about the adequacy of current U.S. law and policy to handle nanoscale innovations and side effects. Bennett argues that although no laws directly address nanotechnology, there exists a class of statutes, values, and norms that apply to emerging technologies as a whole--but which also tend to promote technology adoption. Given the potential side effects of nanotechnology, Bennett concludes that it is essential to approach these innovations cautiously and to ask whether or not "society is mature enough to manage them."

In the assignment, students first had to describe Bennett's essential argument so as to gauge how well they understood it. They were then asked to discuss how the points Bennett raises related to material covered in the class, and to illustrate with at least one example drawn from course lectures. The intention here was to get students to connect course material on nanomanufacuring to the themes expressed in Bennett's essay. Third, students were asked to discuss any issues for policy, law, and society that came to mind but that Bennett didn't cover. The goal here was to encourage students to think beyond the essay, and to see what kinds of examples they would provide. Finally, students were asked to conclude by considering the general role government should adopt in addressing the development and commercialization of nanotechnology. In particular, students were asked to consider the extent to which government can or should regulate a new technology to ensure the protection of public health and safety.

\section{Expectations}

The assignment ran approximately seven pages, and students had one week to write it. As this was a graduate level course, it was expected that students would be able to handle an assignment of this type and length. Similar expectations concerned students' analytical and writing skills, although the faculty recognized that the level of writing might not be up to the norm expected with political science or philosophy graduate students, who are more accustomed to writing in general and about relatively abstract material in particular. The faculty expected that most students would be able to describe the basic argument in the article and to connect issues raised in class lectures to Bennett's themes, but would have a more difficult time thinking about other kinds of issues and, more critically, considering the essential role of government in addressing new technology. Finally, we expected foreign students to have more difficulty on some of these issues given the U.S. centric nature of the lectures and the article.

\section{Performance}

Student performance matched and, in many cases, exceeded expectations. As expected, most students grasped the essential argument raised by the author and were able to connect his arguments to issues raised in class. This being said, in most instances the issues raised were those presented in the three aforementioned course lectures, as opposed to interpreting material offered by engineering or science faculty through the lens of societal or policy impacts. In the future it might be useful to specify a substantive issue (e.g., manufacturing processes) and see how students apply the broader arguments to it.

Not surprisingly, students varied most widely in their capacity to think about gaps in the article's coverage. Most stuck with obvious omissions--for example, that the author focused only on the U.S. (a point Bennett had in fact conceded)--but the best essays were from those students who clearly thought hard about the matter and came up with very good examples that in some instances challenged the articles basic thesis. Finally, there was wide variation in student 
assessment of the proper role of government, ranging from "do nothing and let the market decide" to ensuring that only the most highly educated and informed--the scientific elite, presumably--made policy decisions affecting nanotechnology. Perhaps not surprising, the majority of responses were expressed rather tentatively, with students unsure of their base of knowledge or opinion, but most made an honest effort to say what they believed.

The overall quality of analysis and writing in most instances equaled that of upper-level undergraduate social science students. As expected, most students shied away from conceptual thinking, but were content to apply what they heard in class to the assignment. Some of the variation may also have been the result of the apparent variation in student backgrounds and levels of experience.

\section{Summary of Assessment and Future Needs}

The greatest lesson obtained from the course and policy assignment was the need to integrate discussion of societal and policy issues more evenly throughout the course. For the most part, the lectures were inserted where the schedules permitted, leaving two of three society and policy lectures to the very end. Such timing may have left the impression in some students' minds that societal and policy issues were separate and thus less important. On the other hand, coming last offered the opportunity to conclude the course with the big picture issues that students will face beyond the laboratory. In the main, a more proactive consideration of the integration of societal and policy issues into the course may be warranted.

The second lesson is that engineering education should make more use of essay assignments. Given a clear focus--in this case a reading--and a structured set of instructions, students showed a solid capacity to develop coherent and frequently thoughtful analyses of important social and political problems.

\section{Acknowledgments}

The authors gratefully acknowledge the financial support of the National Science Foundation Grant EEC-0425826.

\section{Bibliography}

1. Michael Bennett, "Does Existing Law Fail to Address Nanotechnoscience?" IEEE Technology and Society Magazine, Winter 2004: 27-32.

2. R. Sandler and W. D. Kay, "The GMO-Nanotech (Dis)Analogy?" Bulletin of Science, Technology, and Society (forthcoming, 2006). 